\title{
A FORMAÇÃO DE PROFESSORES NO ESTADO DE GOIÁS: O DESAFIO DA EDUCAÇÃO INCLUSIVA
}

\section{THE TEACHER PREPARATION IN THE STATE OF GOIÁS: THE CHALLENGE OF INCLUSIVE EDUCATION}

DOI: http://dx.doi.org/10.5965/1984317813012017059

\author{
Yara Fonseca de Oliveira Silva, Jucelia Linhares Granemann - UEG, UFMS
}

\begin{abstract}
RESUMO
No Brasil, o contexto sociopolítico e econômico tem implementado, a partir do conjunto de diretrizes, políticas públicas para a inclusão escolar. O que justifica esse estudo é o fato de ser o debate sobre formação de professores necessário no contexto da escola inclusiva. Em que medida as instituições formadoras como, a universidade e a Secretaria de Estado de Educação e Cultura (SEDUCE) tem conseguido romper com a dicotomia da postura definida para o professor, que ora assume a condição de professor generalista, formação de carácter mais geral e, ora de professor especializado, formação mais específica e direcionada à educação especial, construída historicamente na formação de professor (inicial e continuada) da educação pública brasileira. O referencial teórico parte do conjunto de diretrizes criadas pelo Estado brasileiro, por autores como, Gotti (1998) e Tardif (2012). A metodologia utilizada é de caráter qualitativo e este artigo mostra o resultado parcial dos aspectos teóricos. O Estado de Goiás ao se deparar com a realidade da escola inclusiva tem buscado perceber que o professor é um elemento primordial e é preciso implementar sua formação para alcançar uma prática profissional de qualidade para todos.
\end{abstract}

PALAVRAS-CHAVE: Formação de professoras. Goiás. Educação inclusiva.

\begin{abstract}
In Brazil, the socio-political and economic context has implemented public policies for school inclusion, from the set of guidelines. This study justifies itself by the fact that the debate on teacher preparation is necessary in the context of the inclusive school. How the educational institutions as universities and SEDUCE have managed to break the dichotomy of the professional attitude defined for the teacher, sometimes a more general formation and sometimes more specific, aimed to special education, historically constructed in teacher preparation (initial and continuing) of Brazilian public education. The theoretical framework initiates from the set of guidelines created by the Brazilian State and by authors such as Gotti (1998) and Tardif (2012). The methodology used is in a qualitative way and this article shows the partial result of the theoretical aspects. The State of Goiás when faced with the reality of inclusive school has strived to realize that the teacher is a key element and we need to implement their training to achieve a work experience of quality for all.
\end{abstract}

KEYWORDS: Teacher preparation. Goiás. Inclusive education. 


\section{INTRODUÇÃO}

A sociedade mundial do século XXI vivencia mudanças significativas que redimensionam a forma de olhar seu grupo social. Dentre os movimentos existentes, verificase o Estado na busca de propostas políticas para o equilíbrio da sociedade e os movimentos sociais que lutam pelos direitos humanos, especificamente, as lutas pela igualdade e o respeito à diversidade via tratados internacionais articulados com os estados nacionais, o que geram políticas públicas.

O contexto sociopolítico e econômico do final do século XX até os dias atuais, no Brasil, tem implementado políticas públicas que possibilitam um amplo processo de mudanças na educação. Essas mudanças traduzem-se em reformas no País a partir do conjunto de diretrizes criadas pelo Estado, que, dentre outras, se destacam as seguintes: a Constituição Federal de 1988 (BRASIL, 1988), a Declaração Mundial de Educação para Todos (UNESCO, 1990), Estatuto da Criança e do Adolescente (ECA) de 1990 (BRASIL, 1990), a Declaração de Salamanca (BRASIL, 1994), a Lei de Diretrizes e Bases da Educação Nacional (LDBEN) - Lei nº 9.394, de 20 de dezembro de 1996 (BRASIL, 1996) e a Política Nacional de Educação Especial na Perspectiva da Educação Inclusiva (PNEE-PEI), publicada em 2008 que passa a influenciar a formulação das políticas públicas para a educação inclusiva, partindo do pressuposto de que todo o indivíduo tem direito à educação como meio de alcançar um nível adequado de desenvolvimento, em que características individuais, habilidades e necessidades, que lhe são particulares deverão ser respeitadas. Para isso, os sistemas de ensino devem ser organizados com vistas a atender também um público, cujas diferenças e dificuldades, podem ser mais acentuadas. Nesse grupo, encontram-se também os chamados alunos com deficiência, que segundo, Scotto (2008), exigem um atendimento voltado às suas reais necessidades e condições. Isso implica trabalhar com a diversidade, de forma interativa. A escola deve estar orientada para o acolhimento, aceitação, esforço coletivo e equiparação de oportunidades de desenvolvimento e requer que as crianças com deficiência saiam da exclusão e participem de classes comuns. No entanto, é necessário um diagnóstico cuidadoso que levante as necessidades específicas de cada criança.

Na perspectiva da educação inclusiva tem-se a organização das políticas e legislações em todos os Estados e no Distrito Federal, para o atendimento educacional especializado, para a orientação às famílias e a formação continuada dos professores, constituindo a organização 
da política de educação inclusiva de forma a garantir o atendimento aos alunos com deficiência da rede pública de ensino (BRASIL, 2007).

Nessa direção, o país em suas secretarias de educação declara nos documentos oficiais que dispõe hoje de uma concepção de organização pedagógica das distintas etapas da escolarização e de materiais para dar apoio à reestruturação curricular, que se faz necessária para transformar o novo paradigma curricular da realidade da escola inclusiva. Tomando como base a LDBEN de 1996 e em colaboração com a sociedade e demais esferas federativas, os órgãos educacionais nacionais, executivos e normativos vêm interpretando e regulamentando esses paradigmas curriculares de modo ousado e inovador (BRASIL, 2007).

Atualmente a educação brasileira tem dado destaque para a formação de professores nas instituições formadoras como, a universidade e as secretarias de estado de educação, por ser fundamental uma melhor formação para a melhoria do trabalho pedagógico. A formação continuada emerge da realidade da escola atual que se propõe a ser inclusiva e o professor parte de sua experiência para alcançar melhores resultados no exercício de seu oficio, propondo que o professor reflita sobre seu fazer pedagógico, de acordo com a necessidade de cada docente.

Diante disso, a formação continuada tem sido entendida como uma conquista para os nossos legisladores, por estabelecer uma sintonia entre a formação inicial de professores, os princípios prescritos pela LDBEN, as normas instituídas nas Diretrizes Curriculares Nacionais para a educação infantil, para o ensino fundamental e para o ensino médio, bem como as recomendações constantes dos Parâmetros e Referenciais Curriculares para a educação básica elaborados pelo Ministério da Educação (BRASIL, 2007).

Conforme a LDBEN 9.394/96, em seu Art. 67, é de responsabilidade da escola assegurar "II- aperfeiçoamento profissional continuado, inclusive com licenciamento periódico remunerado para esse fim; V- período reservado a estudos planejamento e avaliação, incluído na carga horária de trabalho" (BRASIL, 1996, p. 27). A Formação Continuada é implementada como uma solução viável para responder às questões diversas que chegam à escola como as orientações legais necessárias para a discussão na escola e para o desenvolvimento do trabalho de professor.

Nesse contexto, esse estudo busca refletir sobre formação de professores no intuito de 
acompanhar as concepções e as práticas desenvolvidas na escola pública brasileira e sinalizar a condição da formação de professores no atual contexto da escola inclusiva. Para tanto, revê a condição histórica, ainda que de forma breve, da formação de professores no Brasil e, em seguida apresenta o caso do Estado de Goiás que se faz presente no cenário educacional. Destaca, portanto, o papel de duas instituições formadoras que são, a universidade enquanto promotora principalmente da formação inicial de professores e as Secretarias de Estado de Educação e Cultura (SEDUCE), a formação continuada do professor.

O que justifica esse tema é o fato de ser necessária uma formação de professores de qualidade ao ponto de contemplar as demandas da escola inclusiva que se faz presente na escola pública brasileira, além de outras questões como, baixa remuneração salarial, falta de adaptações curriculares, condições de infraestrutura física e material. O despreparo dos professores, que é histórico tem sido sinalizado por estudiosos da área (FALSARELLA, 2004; ESTRELA, 2002; MORALES, 2000) como um dos dificultadores para a concretização da inclusão na escola pública brasileira. Esta é uma investigação ${ }^{1}$ teórica, de revisão bibliográfica.

O problema que se apresenta é, em que medida a formação de professores tem se estruturado no contexto da escola inclusiva e como as instituições formadoras como, a universidade e a SEDUCE tem se organizado para oportunizar a formação dos professores?

A hipótese aqui apresentada é que ao longo da história da educação pública brasileira institucionalizou-se uma formação de professor dicotômica, ou seja, uma formação para o professor atuar no ensino regular e outra para atuar no ensino especial, com isso, essa distinção se enraizou provocando a discriminação entre os professores que agora precisam lidar com todo tipo de aluno dentro da proposta da escola inclusiva.

Nesse sentido, entende-se que a formação de professor deve ser ofertada e desenvolvida por todos os professores, pois o professor precisa estar capacitado para atender seja, o aluno "normal" ou com deficiência e de forma articulada no âmbito nacional, regional ou estadual.

O texto está organizado em mais duas seções, além dessa introdução e da conclusão. A primeira seção apresenta uma revisão histórica em que se contempla a formação de

\footnotetext{
${ }^{1}$ Esse artigo contém parte do referencial teórico e da pesquisa de campo desenvolvida pela primeira autora, professora e pesquisadora do Mestrado Interdisciplinar em Educação e Linguagem - PPGIELT/UEG-GO.
} 
professores e, a outra mostra, o caso do Estado de Goiás que se organiza para contribuir com a constituição do sentir e pensar da prática pedagógica desse profissional.

\section{REVISANDO A FORMAÇÃO DE PROFESSORES}

Ao longo desta seção são apresentados diferentes períodos da educação brasileira e a condição da escola - regular e ou especial - no longo século XX, na tentativa de mostrar a evolução da temática: formação de professores. Para essa revisão utilizou-se estudiosos que tratam dessa temática, em especial, Gotti (1998), Schön (1983), Tardif (2002), Tardif e Lessard (2012). A proposta é ilustrar a discussão da formação de professores, suas contradições e alcances que possivelmente se manifestam na atual formação de professores.

A condição da formação de professores na área de educação especial ou para o processo de ensino aprendizagem de alunos com necessidades especiais sempre constituiu uma dificuldade, tanto para atender a esse alunado adequadamente dentro de instituições especializadas como, mais recentemente, para implementar o processo de inclusão de alunos com deficiência nas escolas regulares.

\subsection{FORMAÇÃO DE PROFESSORES E O ATENDIMENTO AO ALUNO COM DEFICIÊNCIA}

Ao rever a história do atendimento aos alunos com deficiência constata-se que nos anos finais do Império a formação ou os cuidados com eles ainda estavam vinculados aos profissionais da saúde e a atuação dos professores ficava sob a dependência dos mesmos. Um pouco mais adiante, nos anos 20 do século passado, houve uma crescente preocupação com a dimensão propriamente pedagógica da ação educativa voltada para esse alunado, porém estreitamente influenciada pela abordagem psicológica sem abandonar o campo da saúde.

Sob essa ótica, postulava-se, em 1930, uma formação comum a todos os professores, tanto no que se refere ao conteúdo quanto à prática, que deveria possibilitar-lhes experiências com as crianças ditas "normais" e com as consideradas deficientes. Porém, com a estruturação das Escolas Pestalozzi, caminhou-se em sentido contrário, pois os alunos com deficiência eram confinados em escolas especiais provavelmente desviando a estruturação e os 
atendimentos destinados a esse alunado pelas diferentes instituições especializadas.

Diante disso, nesse contexto histórico a formação dos profissionais da educação se deu em dois ramos distintos: os que deverão atuar no ensino regular e os que atuarão na educação especial. E essa formação diferenciada somente veio reforçar o modelo que se baseia na eficiência, na seleção dos melhores e na exclusão social de muitos, fundado em uma visão "desfocada" da realidade e do indivíduo.

Acredita-se que essa dicotomia dentro da formação de professores provavelmente provocou uma discriminação e institucionalizou-se uma distinção no ponto de partida da formação, negando, portanto, o princípio da "integração", não só do deficiente na rede regular de ensino, como também do profissional da educação na realidade educacional existente sendo, o professor ou da escola regular ou da classe especial ou da instituição especializada, etc.

Negou-se a esses profissionais a experiência de conviver com a diferença e com as dificuldades dela decorrentes. Pois, sem uma formação teórica e prática desses professores, básica e comum a todos, diminuiu-se a garantia de uma leitura crítica, de propostas de mudanças e uma consciência clara das determinações sociais, políticas e econômicas presentes na instituição escolar.

Para Gotti (1998), na década de 1960, a frequência de alunos com deficiência em escolas regulares ampliou-se consideravelmente, o que veio consolidar a formação de professores especializados, em nível de ensino médio, com formação continuada a partir de estudos adicionais ou cursos de aperfeiçoamento.

Nos anos de 1970, mesmo que lentamente, iniciou-se no Brasil a formação de professores em nível superior para atuação na educação especial. Porém Gotti (1998), enfatiza que apesar dessas iniciativas, ainda se observam lacunas nessa formação como, as carências de recursos materiais e estruturais apresentadas pela maioria dos professores e pelas escolas do ensino regular que atendem alunos com deficiências.

As décadas de 1980 e 1990, foram marcadas por um período em que ocorreram mudanças nos determinantes socioeconômicos e políticos, impulsionando a expansão do ensino superior, o que possibilitou a formação do professor em nível superior com a tentativa de proporcionar um conhecimento que desenvolvesse habilidades, práticas e ações para uma 
escola que de fato e de direito atendesse a qualquer tipo aluno, seja ele, o dito normal ou o com deficiência e, portanto, entendeu-se que essa proposta de formação de professores não seria mais paralela e distinta, como anteriormente existia, uma formação para lidar com alunos da escola regular e outra para os de escola especial.

No final da década de 1990 e no inicio do Século XXI o compromisso que a escola pública e gratuita assume é de acolher a todos, realizar a socialização e dar formação cultural e científica aos seus alunos e, ainda buscar contribuir com a formação do sujeito, no sentido de aprenderem a viver em comunidade, respeitando as limitações e as diferenças de cada sujeito.

No campo curricular, os principais problemas identificados na formação inicial de professores são: a) desconsideração do repertório de conhecimentos dos professores no planejamento e desenvolvimento de ações pedagógicas; b) o uso desarticulado e o tratamento inadequado dos conteúdos das várias áreas do conhecimento na prática pedagógica; c) a falta de oportunidades para o seu desenvolvimento cultural; d) o tratamento restritivo da sua atuação profissional, ligado tão-somente à preparação para a regência de classe, deixando de lado outras dimensões fundamentais, como a sua participação na formulação do projeto político-pedagógico da escola, o seu relacionamento com alunos e com a comunidade; e) a ausência de estímulo para se desenvolver uma postura investigativa, capaz de relacionar teoria e prática; f) a ausência de conteúdos relativos às novas tecnologias da informação e comunicação; g) a desconsideração das especificidades próprias dos níveis e/ou modalidades de ensino em que são atendidos os alunos da educação básica; h) a desconsideração das especificidades das áreas do conhecimento que compõem o quadro curricular na educação básica (MEC, 2000, p. 24).

A Proposta de Diretrizes para a Formação de Professores da Educação Básica propõe dentre outras questões, o desempenho do papel docente frente às novas concepções de educação do mundo contemporâneo e impõe exigências como a de orientar e mediar o ensino para a aprendizagem dos alunos (MEC, 2000). Diante disso, é preciso romper com as fragilidades que invadem a instituição escolar que agora deve ser inclusiva, se adaptando para receber e fazer permanecer todo tipo de aluno e, portanto, repensar a maneira como está organizada a formação dos professores, a começar pela própria noção que se tem dos saberes e de conhecimentos necessários a esse profissional. 


\subsection{FORMAÇÃO DE PROFESSORES: SABERES E PRÁTICAS}

No inicio do Século XXI a temática de formação de professores, sua prática e os saberes indispensáveis ao docente tem sido alvo de discussão em todo o cenário mundial.

De acordo com Tardif (2002, p. 6),

[...] na América do Norte e na maioria dos outros países de cultura anglosaxônica (Austrália, Inglaterra e etc.), bem como, de forma mais recente, na Europa francófona (Bélgica, Franca e Suíça), toda a área educacional está mergulhada em uma vasta corrente de profissionalização dos agentes da educação em geral e dos professores em particular [...] também encontramos essa corrente em vários países latino-americanos.

O Brasil recebe influencias de diversos teóricos como, Schon (2000), Tardif; Lessard (2012), Pimenta (2005) e Libâneo et al. (2012), definem posições sobre a condição de ser professor, assim, contemplam as atribuições, habilidades e elementos primordiais para a formação inicial e continuada de professores. Esses autores têm em comum a reação contra o denominado pensamento tradicional, que segundo Tardif (2002), alienava o profissional, negligenciando aspectos essenciais a sua formação como sujeito da prática pedagógica que se exerce mediante o pensamento reflexivo. Portanto, os autores supracitados acreditam na prática reflexiva como peça fundamental no processo de construção do saber, partindo do pressuposto de que, só por intermédio da transformação de um professor prático em um professor ativo, autônomo, reflexivo que é possível alcançar mudanças significativas.

Nesse movimento vários autores nacionais e internacionais caminham em múltiplas direções e, embora enfatizem pontos diferentes, como ser um professor pesquisador ou profissional reflexivo, essas proposições têm raízes comuns, pois todas elas valorizam a articulação entre teoria e prática na formação docente.

Em relação ao pensamento reflexivo é possível dizer que consiste numa sequência ordenada, consecutiva e engendrada de ideias, o ato de refletir ocorre por meio de um processo autônomo, sendo uma volta da consciência e do espírito sobre si mesmo, portanto, é necessária a conscientização da necessidade de internalização do conhecimento, a partir da formação inicial do profissional, na busca constante de aprimoramento, aliada à 
responsabilidade pelo seu próprio desenvolvimento cognitivo. Neste sentido, busca-se compreender o papel do professor como sendo primordial no processo de construção do saber dos educandos (FERREIRA; AGUIAR, 2001).

Quanto à discussão do conceito de professor-pesquisador define como uma complexa tarefa a atitude analítica e o espírito de investigação que têm de existir. Para Schon (2000), professor-pesquisador é aquele que congrega as condições de ser ativo, crítico e autônomo, que denuncia a submissão a que o professor vem sendo submetido. $O$ que distingue o professor reflexivo do pesquisador é que, todo professor-pesquisador tem de ser reflexivo, mas o professor reflexivo não é, necessariamente um pesquisador.

Contreras (2002) afirma que o professor deve ter uma boa formação teórica para o processo de reflexão, reivindica um conteúdo crítico sintonizado com as necessidades mais amplas do contexto da escola e ainda prescreve que a perspectiva transformadora deve dar-se coletivamente sendo o compromisso com a transformação da realidade e a sensibilidade aberta ao pluralismo.

Um outro raciocínio sobre os saberes e competências necessários do professor é desenvolvido por Libâneo (2001, p. 69), para quem

saberes são conhecimentos teóricos e práticos requeridos para o exercício profissional, competências são as qualidades, capacidades, habilidades e atitudes relacionados com esses conhecimentos teóricos e práticos e que permitem a um profissional exercer adequadamente sua profissão.

Neste sentido, interpreta-se que o professor motivado a pensar, a buscar a sua autonomia cognitiva e didático-pedagógica, que englobe, em seu contexto, conteúdo, procedimentos e atitudes possa ter habilidade para fazer e atuar como sujeito pensante, capaz de construir o seu próprio conhecimento e, por isto mesmo, dotado do poder de questionar processos e procedimentos, é o pretenso professor ideal nessa "sociedade do conhecimento"2.

A sociedade atual indica que a perspectiva para os docentes é a de desenvolver estímulos e subsídios, de tal modo que a busca do conhecimento seja baseada no saber científico, todavia significativo para a sua atuação, enquanto mediador do saber. Pois, é 
inerente a capacidade de pensar do homem, mas o aprender a pensar e o aprender a aprender constituem-se em atividades que precisam ser estimuladas. Quanto à instituição escolar, por sua vez, a indicação é pela sua função de mediar a construção e a reconstrução da cultura, expressando a qualidade cognitiva e operativa das experiências de aprendizagem, tanto de alunos, quanto de professores.

Assim, a formação de professor se faz primordial no processo de reforma política, pois na atualidade o intento é por uma sociedade inclusiva que gradativamente busca em vários setores da sociedade: no mercado de trabalho ${ }^{3}$, no esporte ${ }^{4}$, na cultura ${ }^{5}$, nas artes, na religião e na educação, garantir a todos os seus diversos espaços. A definição que se tem de educação inclusiva implica a busca de uma sociedade para todos e deve contribuir na formação de cidadãos que aprendam que pertencer a esta sociedade é um direito, que, obviamente implica deveres, e não uma dádiva dos governantes.

A educação inclusiva propõe então o respeito às necessidades especiais e às diferenças e propugna pela igualdade de direitos de todos enquanto cidadãos, diferentemente da desigualdade, que propicia condições de exploração, de competição e de produção de inferioridade. A inclusão parte do princípio de que todos são diferentes e a sociedade deve considerar com igualdade essas diferenças.

Sendo assim, a partir da revisão bibliográfica realizada, o contexto atual do século XXI precisa que a universidade e a secretaria de educação dos estados brasileiros invistam em cursos de formação que se proponham assumir o papel de desenvolver a formação de qualidade de seus professores. E esta é a questão que se persegue, "como" a formação de professores vem se apropriando dessa proposta no nível real da educação inclusiva que se dá a partir dos dispositivos legais. A seção a seguir descreve a forma como as duas principais instituições ligadas à formação de professores tem se apropriado do conhecimento do conjunto de legislações que se estabelecem no cenário estadual goiano.

\footnotetext{
${ }^{3}$ Concursos públicos-empresas têm obrigatoriamente de oferecer vagas para pessoas com necessidades especiais.

${ }^{4} \mathrm{O}$ governo de Goiás está oferecendo, por intermédio da Agência Goiana de Esporte e Lazer (AGEL), o Programa Bolsa Esporte que incentiva pessoas com deficiência ao esporte.

${ }^{5}$ Criada no ano de 1999, a Agência Goiana de Cultura Pedro Ludovico Teixeira (AGEPEL) - órgão do governo responsável pela política cultural do Estado de Goiás.
} 


\section{FORMAÇÃO INICIAL E CONTINUADA DO PROFESSOR NO ESTADO DE GOIÁS: UEG E SEDUCE}

A revisão histórica realizada na seção anterior, a qual buscou contemplar a formação de professores, tem se praticamente como unanimidade a concordância que, para assegurar um processo de ensino e de aprendizagem de qualidade, na perspectiva da educação inclusiva, é necessária a implantação de uma politica de formação de professores e um projeto pedagógico que atenda às demandas e à realidade educacional, levando-se em consideração a comunidade a que se destina.

O Estado de Goiás no final do século XX acompanha as transformações da sociedade moderna e a condição de alternância do papel do Estado na economia capitalista, ora de maior regulação, ora de maior liberalização na nova configuração da sociedade moderna. Nesse contexto percebe-se que no início do século XXI diferentes instituições são chamadas a repensar e criar uma nova realidade. Diante disso, politicas educacionais têm sido formuladas pelo estado brasileiro, tanto em sua formação inicial pela universidade, como pelas suas Secretarias de Estado de Educação e Cultura (SEDUCE) que expressam a intenção de alterar as condições da escola regular no sentido de torná-la de fato inclusiva.

Essa seção apresenta o resultado parcial de dados coletados a partir do levantamento bibliográfico da pesquisa em andamento da primeira autora referente à formação de professores. Portanto, apresenta a condição de duas instituições no contexto da educação inclusiva com foco na formação de professores. A primeira instituição é a Universidade Estadual de Goiás $^{6}$ que possibilitou a ampliação da formação inicial de professores no ensino superior e, a segunda instituição é a SEDUCE responsável por significativa parcela da proposta de formação continuada.

As mudanças na educação brasileira ocorrem a partir do proposto nos documentos oficiais que deveriam ser cumpridas, como a Lei de Diretrizes e Bases da Educação Nacional (LDBEN, 1996), Lei n. 9.394/1996 e o $1^{\text {o }}$ Plano Nacional de Educação (PNE), de 2000. Em Goiás tem-se a expansão do ensino superior e a implementação da escola inclusiva no final do século XX, o que decorreu em mudanças institucionais, tanto para o ensino superior como, para a escola básica.

${ }^{6}$ Consolidada pelo governo do Estado por meio da Lei no 13.456 , de 16 de abril de 1999. 
No ensino superior tem-se a materialização da reforma com a abertura de diversas instituições que objetivavam, em primeira instância, formar professores para acessar ou permanecer na área de ensino e, proporcionar a interiorização do ensino superior nesse Estado.

Ao mesmo tempo na escola básica, o professor deve agora saber lidar com as diferenças, face às exigências de que os alunos devem aprender juntos, independentemente de quaisquer dificuldades ou diferenças que possam ter. As escolas devem reconhecer e responder às diversas necessidades de seus alunos, considerando a diversidade humana; o outro, que não é igual; acomodando tanto estilos como ritmos diferentes de aprendizagem e assegurando uma educação de qualidade a todos, através de um currículo apropriado, de modificações organizacionais, novas estratégias de ensino, uso de recursos e parcerias com a comunidade.

Assim, o Estado de Goiás no atendimento da LDBEN de 1996, a qual determina a obrigatoriedade de formação em nível superior a todos os profissionais da educação, garante essa formação criando a UEG, que consistiu na reunião de 13 faculdades estaduais isoladas, em uma única universidade que já nascia interiorizada.

Goiás, na contramão das reformas neoliberais, que tendem a aumentar a privatização do ensino, cria mecanismos para democratizar o acesso ao ensino superior pela via pública, ampliando suas conquistas sociais no campo da educação. Assim, o governo estadual goiano propõe formação superior para os profissionais da educação e a partir da UEG privilegia o grupo de professores que estavam ou que pretendiam fazer parte do quadro de trabalhadores da Secretaria de Educação Estadual expandindo e interiorizando o ensino superior no Estado, cumpre, ao mesmo tempo, com a obrigatoriedade da lei.

A UEG assume a responsabilidade definida pelo Governo do Estado de Goiás, conforme a Lei n. 16.272/2008 que, em seu Art. $6^{\circ}$, determina que se tenha qualificação e, ainda capacitação de profissionais em várias áreas de abrangência do ensino, da pesquisa e da extensão universitária (GOIÁS, 2008), exemplo disso, foi a realização do Curso Emergencial de Licenciatura Plena ${ }^{7}$, que consistia na formação em nível superior para os professores em exercício.

\footnotetext{
${ }^{7}$ Projeto do governo do Estado de Goiás, conhecido como Parceladas, criado durante a Década de Educação (1997-2007), para capacitar professores da rede pública e privada em atendimento à LDBEN de 1996. Desenvolvidas com diferentes parcerias como a Secretaria Estadual de Educação, Secretaria Municipal de Educação e outras.
} 
Percebe-se que o foco da política da UEG foi a expansão periférica, se tornando uma das maiores universidades brasileiras em quantidade de campi e aumentando, significativamente, o número de campus e de atendimentos. Porém, as atividades acadêmicas são oferecidas, predominantemente, no turno noturno e com foco no ensino, principalmente com cursos de licenciatura para a área de formação de professores. Atualmente, a UEG conta com 42 campus, sendo uma voltada para Educação a Distância, cinco polos universitários e 15 polos de ensino a distância, presentes em 49 dos 246 municípios goianos (UEG, 2000).

O maior desafio que enfrenta o ensino superior, no entanto, é o da qualidade dos profissionais que forma, ainda que o Governo, com seu papel de órgão financiador e regulador tente propor politicas para alcançar a formação inicial e continuada de professores.

O Estado de Goiás adotou, desde 1999, através da Secretaria de Educação do Estado Goiás, via Superintendência de Ensino Especial, a proposta de efetivação da educação inclusiva, em atendimento aos novos paradigmas educacionais, cuja orientação jurídica tem as suas bases na Lei de Diretrizes e Bases do Sistema Educativo Goiano,

Lei n. 26/98, que considera a aproximação dos pressupostos e das práticas sociais da educação para todos. Na busca de uma educação com qualidade e equidade para todos, na qual os sistemas de ensino devem matricular todos os alunos, prescrevendo-se que, a escola deve organizar-se para o atendimento de seus alunos com qualidade.

Por isto, um dos pontos centrais desta discussão é refletir a formação de professores neste contexto que, por um lado, prima pelo discurso da igualdade de valores entre os seres humanos e, como tal, pela garantia da igualdade de direitos entre eles e, por outro, não mais comporta a existência da ignorância, excluindo seres humanos de um ritmo de produção cada vez mais vital à crescente competitividade, por lhes dificultar o exercício pleno de um de seus direitos como cidadão: o de ser trabalhador produtivo.

A proposta de formação inicial do professor nas licenciaturas, no curso de pedagogia tem contemplado poucos componentes curriculares voltados para a educação especial e, a de formação continuada, tem sido, em sua maioria aligeirada e com carga horaria mínima ofertada principalmente pelas secretarias de educação.

O que se constata, como fragilidade é a falta de informação e de formação desses profissionais sobre as condições dos alunos especiais ou com deficiências - suas causas, 
consequências, recursos e alternativas, pois é notória a distância entre teoria e prática. Por isso, independente das dificuldades, a formação inicial e continuada deve ser ofertado a todo professor, pois a proposta da escola inclusiva visa uma mudança na profissionalidade ${ }^{8}$ de tal forma que este se torne capaz de tomar iniciativas que favoreçam à plena escolarização de todos os alunos, conhecendo-os: suas possibilidades e limitações. Portanto, o professor qualquer que seja ele, tem recebido responsabilidades crescentes diante desta realidade, necessitando que tenha informações apropriadas, a respeito das dificuldades do aluno com deficiência, dos seus processos de aprendizagem e do seu desenvolvimento social e individual. E ainda, deverá este professor entender a necessidade de ir além dos limites que os alunos revelam, no sentido de levá-los a alcançar o máximo da exploração e do desenvolvimento de suas potencialidades. Aos professores é requerido tornarem-se mais próximos dos alunos, na captação e interpretação de suas maiores dificuldades.

A escola pública estadual goiana tem tentado criar condições, estruturas e espaços para a diversidade de educandos, mas a escola só poderá vir a tornar-se inclusiva quando conseguir transformar não apenas a rede física, mas principalmente, a formação do professor, no sentido de tornar o mesmo capaz de ensinar e aprender, diante da diversidade do alunado.

Em relação à formação continuada oferecida pela SEDUCE tem-se a busca, de alguns professores da rede pública, de traduzir os saberes desenvolvidos pelos professores dentro do processo de ensino aprendizagem estimulando grupos de estudos para discutir a partir de relatos e histórias de vida dos professores uma forma de lidar com a inclusão nas escolas públicas do estado de Goiás. Assim, aos poucos, os professores têm tentando provocar a partir da reflexão de suas experiências uma nova forma de pensar e sentir a sua própria prática pedagógica.

A proposta da escrita de um documento pessoal do professor(a) tem mostrado como se constitui a subjetividade instaurada em cada sujeito e resgata as experiências educativas formais e não formais podendo enriquecer a prática pedagógica do professor, possibilitando a reflexão e a reelaboração da síntese de conhecimento construído no decorrer da trajetória do sujeito e, portanto, do profissional.

A par disso, as histórias de vida construídas pelos professores que se encontram

\footnotetext{
8 Entende-se por profissionalidade o "que é específico na ação docente, isto é, o conjunto de comportamentos, conhecimentos, destrezas, atitudes e valores que constituem a especificidade de ser professor" (SACRISTAN, 1995, p. 65.).
} 
diretamente ligados ao processo de inclusão escolar se propõem a resgatar a prática pedagógica do atendimento educacional inclusivo e, apresentam o valor e o significado dessas para a formação do professor, principalmente a continuada, por acreditar que as histórias de vida podem acrescer e contribuir com a formação e a prática pedagógica do professor.

Nesse sentido, entende-se que a produção de conhecimento de cada um dos profissionais e ou estudantes a partir de suas vivências possibilita o desenvolvimento de uma docência que de fato contribua com inclusão da educação pública goiana no sentido de avançar para uma prática mais integradora e menos fragmentada e reducionista.

Diante disso, entende-se que as instituições que tratam da formação de professores no Estado de Goiás, ao se deparar com a realidade da educação inclusiva, tem implementado ações que buscam em certa medida perceber o professor como um elemento primordial. Ainda que se tenha muitas fragilidades a serem superadas, diante do processo histórico discriminador da educação brasileira e da formação de professores é, possível dizer que o conjunto de leis que afirmam o direito a educação inclusiva tem provocado mudanças no estado goiano e a luta pela contínua ampliação das possibilidades para uma formação de professores com qualidade.

\section{CONCLUSÃO}

A formação inicial e continuada de professores é tanto um desafio como uma das estratégias para permitir a efetiva aprendizagem de todo e qualquer aluno. O professor do século XXI precisa de uma formação sólida, de desenvolvimento de habilidades básicas para ensinar a convivência na sociedade que é diversa e que, em seu processo de formação contemple a articulação entre teoria e prática que vão constituindo seus saberes.

Nesse caminhar, é importante destacar que, de modo geral, a formação recebida pelos professores influencia diretamente no desenvolvimento dos alunos. Na situação específica aqui estudada, o professor aparece como figura indispensável para prover o apoio e a orientação segura ao desenvolvimento e a evolução do aluno. Por outro lado, isto ocorre de forma mais intensa quando, a partir de sua formação, o professor alimenta sua própria capacidade reflexiva no trabalho em equipe. Como salienta Ainscow (1997), a reflexão crítica em equipe é fundamental para criar as condições para a implementação da educação inclusiva. 
Nessa perspectiva, portanto, o atual e grande desafio posto para os cursos de formação de professores é o de produzir conhecimentos que possam desencadear novas atitudes que permitam a compreensão de situações complexas de ensino, para que os professores possam desempenhar de maneira responsável e satisfatória seu papel de ensinar e aprender para a diversidade. Para tanto, faz-se necessário elaborar políticas públicas educacionais voltadas para práticas mais inclusivas, adequar a formação de professores às novas exigências educacionais e definir um perfil profissional do professor, ou seja, habilidades e competências necessárias aos professores de acordo com a realidade brasileira (NUNES SOBRINHO; NAUJORKS, 2001). Essas parecem ser, hoje, medidas urgentes a serem adotadas para que ocorra uma mudança no status quo da educação inclusiva.

Nesse processo, é possível concluir que o profissional que trabalha com a educação especial deve ser um professor qualificado, dotado de uma consciência lúcida de sua realidade histórica e dos problemas dela emergentes. Somente dessa maneira esse educador poderá contribuir para a diminuição da segregação e da exclusão dos diferentes da sociedade. Nesse sentido, a formação de professor é apontada como nuclear nesse processo de educação inclusiva, por estar inserida nesse mundo de mudanças e, portanto, precisa ser repensada com bases nas novas realidades e exigências da contemporaneidade.

\section{REFERÊNCIAS}

AINSCOW, M.; PORTER, G.; WANG, M. Caminhos para escolas inclusivas. Lisboa: Instituto de Inovação Cultural, 1997.

BRASIL. Constituição da Republica Federativa do Brasil. São Paulo: Atlas, 1988.

. Declaração de Salamanca e Linha de Ação sobre Necessidades Educativas Especiais. Brasília: CORDE, 1994.

. Lei n. 9.394, de 20 de dezembro de 1996. Estabelece as diretrizes e bases da educação nacional. Diário Oficial [da] República Federativa do Brasil, Brasília, 23 dez. 1996, p. 27833. Disponível em: <http://www.planalto.gov.br/ccivil_03/leis/L9394.htm>. Acesso em: 14 fev. 2016.

. Conselho Nacional de Educação. Proposta de Diretrizes para a formação inicial de professores da educação básica, em cursos de nível superior. Brasília, maio 2000.

. Plano Nacional de Educação (Lei n. ${ }^{\circ}$ 10.172/01). 2000. 
. Lei $\mathrm{n}^{\circ} 8.069$, de 13 de julho de 1990. Dispõe sobre o estatuto da criança e do adolescente e dá outras providências. Diário Oficial [da] República Federativa do Brasil, Brasília, DF, 16 jul. 1990, p. 13563. Disponível em: <http://www.planalto.gov.br/ccivil_03/leis/L8069.htm>. Acesso em: 14 fev. 2016.

. Ministério da Educação e Cultura. Plano nacional de formação de professores na educação básica. Brasília: MEC, 2007.

Política Nacional de Educação Especial na perspectiva da Educação Inclusiva. Brasília: MEC/SEESP, 2008.

CONTRERAS, J. A autonomia de professores. São Paulo, SP: Cortez, 2002.

ESTRELA, M. T. Relação pedagógica, disciplina e indisciplina na sala de aula. 4. ed. Porto Portugal: Porto Editora, 2002.

FALSARELLA, A. M. Formação continuada e prática de sala de aula. Campinas, SP: Autores Associados, 2004.

FERREIRA, N. S. C.; AGUIAR, M. A. da S. Gestão da educação: impasses, perspectivas e compromissos. 2. ed. São Paulo: Cortez, 2001.

GOIÁS. Lei n. 13.456, de 16 de abril de 1999. Dispõe sobre a organização da administração direta, autárquica e fundacional do Poder Executivo e dá outras providências. Diário Oficial do Estado, Goiânia, GO, 20 abr. 1999. Lei de criação da Universidade Estadual de Goiás (UEG). Disponível em: $<$ http://www.cdn.ueg.br/arquivos/legislacao/conteudoN/202/Lei_13.456-Criacao_da_UEG.pdf $>$. Acesso em: 20 out. 2011.

GOTTI, M. O. Integração e inclusão: nova perspectiva sobre a prática da educação especial. In: MARQUEZINE, M. C.; ALMEIDA, M. A.; TANAKA, E. D. O. (Org.). Perspectivas multidisciplinares em educação especial: inclusão. Londrina: Editora da UEL, 1998.

LIBÂNEO, J. C. Pedagogia e pedagogos: inquietações e buscas. Educar, Curitiba, n. 17, p. 153-176, 2001.

LIBÂNEO, J. C.; OLIVEIRA, J. F.; TOSCHI, M. S. Educação escolar: políticas, estrutura e organização. 10. ed. São Paulo: Cortez, 2012.

MORALES, P. A relação professor-aluno. 2. ed. São Paulo: Loyola, 2000.

NAUJORKS, M. I.; NUNES SOBRINHO, F. de P. (Org.). Pesquisa em Educação Especial: $o$ desafio da qualificação. Bauru: Edusc, 2001.

PIMENTA, S. G.; ANASTASIOU, L. G. C. (Org.). Docência da universidade. São Paulo: Cortez 2005.

RIFKIN. J. A era do acesso. São Paulo: Makron Books, 2001.

SACRISTÁN, J. Gimeno. Currículo e diversidade cultural. In: SILVA, T. T. da; MOREIRA, A. F. (Org.). Territórios contestados: o currículo e os novos mapas políticos e culturais. Petrópolis: Vozes, 1995. 
SCHÖN, D. A. Educando o profissional reflexivo: um novo design para o ensino e a aprendizagem. Trad. Roberto Cataldo Costa. Porto Alegre: Artmed, 2000. 256 p.

. The reflective practitioner: how professionals think in action. London: Temple Smith, 1983.

SCOTTO, Arlete. A inclusão escolar na rede de ensino estadual. Disponível em:

.http://www.crmariocovas.sp.gov.br/ent_aphp?

TARDIF, M. Saberes docentes e formação profissional. 4. ed. Rio de Janeiro: Vozes, 2002.

TARDIF, M.; LESSARD, C. O trabalho docente: elementos para uma teoria da docência como profissão de interações humanas. Petrópolis, RJ: Vozes, 2012.

UEG-Universidade Estadual de Goiás. Plano estratégico de desenvolvimento Institucional - PEDI 2001 a 2004 - no processo da implantação e consolidação da UEG. Anápolis: UEG, 2000.

UNESCO. Declaração mundial de educação para todos e plano de ação para satisfazer as necessidades básicas de aprendizagem. Jomtien, 1990. 